\title{
POLÍTICAS NEOLIBERAIS E ENSINO REMOTO \\ EMERGENCIAL: REFLEXÕES POSSÍVEIS NO ESTÁGIO \\ SUPERVISIONADO
}

\author{
Gabriel Silveira Faria ${ }^{1}$ \\ André de Paula Silva²
}

Sandra de Castro de Azevedo 3

RESUMO: O estágio supervisionado é um importante momento na formação inicial, uma vez que permite ao futuro profissional vivenciar o campo de trabalho onde vai atuar e fazer uma reflexão teórica sobre o que observa e sobre suas práticas. Este artigo é resultado de um estágio supervisionado com atitude investigativa realizado durante o ensino remoto emergencial, além das atividades didático-pedagógicas e do processo ensino aprendizagem, este estágio se dedicou também a identificar as políticas neoliberais que estão presentes na educação e que aparecem de forma direta ou indireta no cotidiano do professor da educação básica. Acompanhar aulas, reuniões da gestão, reuniões por área e conselho de classes permitiu perceber como a política neoliberal transforma a gestão da escola em formato de empresa, ataca a autonomia docente e da gestão e intensifica a ideia de meritocracia nos alunos. Um estágio docente realizado de forma investigativa, mesmo no ensino remoto, pode contribuir para a formação inicial docente, desde que a relação entre a universidade e a escola seja de proximidade e confiança.

PALAVRAS-CHAVE: Formação Docente; Política Educacional; Projeto de Vida; Ensino Médio em Tempo Integral.

\section{NEOLIBERAL POLICIES AND EMERGENCY REMOTE EDUCATION: POSSIBLE REFLECTIONS IN THE SUPERVISED INTERNSHIP}

\begin{abstract}
The intership supervised is an important moment in initial training, as allows future professionals to experience the field of work where they will work and make a theoretical reflection on what they observe and their practies. This article is the result of supervised intership with an investigative attitude, during emergency remote teaching.

\footnotetext{
${ }^{1}$ Discente do Curso de Geografia Licenciatura da Universidade Federal de Alfenas (UNIFAL-MG) e bolsista de IC FAPEMIG ; gabriel.faria@sou.unifal-mg.edu.br

${ }^{2}$ Professor de Geografia na SEE-MG e Mestre em Geografia (UNIFAL-MG); andre.paula@sou.unifalmg.edu.br

3 Professora Doutora Associada na Universidade Federal de Alfenas -MG (UNIFAL-MG); sandra.azevedo@unifal-mg.edu.br
} 
FARIA, G. S; SILVA, A. P; AZEVEDO, S. C. Políticas neoliberais e ensino remoto emergencial...

Besides to pedagogical didactic activities ande teaching-learning process, this intership was also dedicated to identifying the neoliberal policies that are present in education and that appear directly or indirect in the daily life life of the basic education teacher. Monitoring classes, management meetings, meetings by area and class coucil allouws us to understand how the neoliberal policies transform school management into a company format, attacks teaching ond management autonomy and intensifies the idea of meritocracy in students. A teaching intership carried out in a investigative manner, even in remote teaching, con contribute to initial teacher training, as long the relationship between the university and the school is on of proximity and trust.

KEY WORDS: Teacher Training; Educational Policies; Life Project; Full Time High School.

\section{POLITIQUES NÉOLIBÉRALES ET TÉLÉÉDUCATION D'URGENCE: RÉFLEXIONS POSSIBLES DANS LE STAGE SUPERVISÉ}

RESUMÉ: Le stage encadré est un moment important à la formation initiale, car il permet aux futurs professionnels d'expérimenter le domaine de travail où ils vont travailler et de faire une réflexion théorique sur ce qu'ils observent et sur leurs pratiques. Cet article est le résultat d'un stage supervisé avec une attitude d'investigation réalisé lors de l'enseignement à distance d'urgence. En plus des activités didactiques pédagogiques et du processus d'enseignement-apprentissage, ce stage a également été consacré à identifier les politiques néolibérales qui sont présentes dans l'éducation et qui apparaissent directement ou indirectement dans la vie quotidienne de l'enseignant de l'éducation de base. Regarder des classes, les réunions de direction, les réunions par quartier et le conseil de classe ont permis de comprendre comment la politique néolibérale transforme la gestion scolaire en format d'entreprise, alors qu'elle attaque l'autonomie d'enseignement et de gestion et intensifie l'idée de méritocratie chez les élèves. Un stage d'enseignement réalisé de manière enquête, même lors de l'enseignement à distance, peut contribuer à la formation initiale des enseignants, autant que la relation entre l'université et l'école soit une relation de proximité et de confiance. MOTS CLÉS: Formation des Enseignants; Politique Éducative; Projet de Vie; Lycée à Temps Plein.

INTRODUÇÃO

Compreender o estágio como a junção da teoria com a prática na formação docente é simplificar o papel do estágio, ou até mesmo colocar uma polaridade entre esses conceitos onde na prática o processo teórico é outro. O estágio tem que ser compreendido como formador da práxis no processo de formação 
FARIA, G. S; SILVA, A. P; AZEVEDO, S. C. Políticas neoliberais e ensino remoto emergencial...

docente, e somente quando compreendido dessa maneira poderá haver construção de saber. Durante a disciplina Orientação de Estágio Supervisionado e Práticas Pedagógicas I do curso de Geografia Licenciatura da Universidade Federal de Alfenas, um grupo de oito alunos realizaram estágio, no primeiro semestre de 2021, em uma escola estadual do estado de Minas Gerais de ensino médio integral e integrado que se encontrava em formato de ensino remoto.

Analisar então a escola durante o ensino remoto emergencial através do estágio foi um grande desafio, num primeiro momento pela falta de aulas, devido à ausência dos alunos nas aulas virtuais. Em segundo lugar, por não haver a presença física das interações e trocas, que só ocorrem presencialmente, e terceiro por não existir uma formação tanto do professor, quanto do aluno e do estagiário acerca da utilização de tecnologias que viabilizam o ensino emergencial.

Como a quantidade de aulas com presença de alunos era baixa, para completar a carga horária do estágio os estagiários participaram de reunião de módulos, sábados letivos e conselhos de classe. Essa vivência da escola possibilitou analisar a conjuntura escolar atual, principalmente no que se refere à política de ensino remoto de Minas Gerais e o Novo Ensino Médio.

O presente trabalho se desenvolve com essas duas premissas: a primeira de compreender o desafio do ensino remoto emergencial, como a escola e a universidade estão se desdobrando para produzir o ensino-aprendizagem na formação básica e na formação docente; segundo em analisar como as instâncias dentro da gestão escolar estão inseridas em políticas neoliberais que trazem consequências aos alunos e professores.

\section{METODOLOGIA}

Este artigo tem sua base no estágio com atitude investigativa realizado durante o estágio supervisionado vinculada à disciplina de Orientação de Estágio Supervisionado e Práticas Pedagógicas I. Sobre essa perspectiva de 
FARIA, G. S; SILVA, A. P; AZEVEDO, S. C. Políticas neoliberais e ensino remoto emergencial...

estágio, Pimenta e Lima (2006, p. 7) afirmam:

\begin{abstract}
Para desenvolver essa perspectiva, é necessário explicitar-se os conceitos de prática e de teoria e como compreendemos a superação da fragmentação entre elas a partir do conceito de práxis, o que aponta para o desenvolvimento do estágio como uma atitude investigativa, que envolve a reflexão e a intervenção na vida da escola, dos professores, dos alunos e da sociedade.
\end{abstract}

As atividades no campo da escola aconteceram no período de 01 de junho de 2021 até 15 de julho de 2021, sendo realizadas de forma concentrada, uma vez que o calendário da universidade não estava alinhado ao calendário das escolas estaduais de Minas Gerais. Diante do desafio do estágio em formato remoto, a orientadora de estágio optou por concentrar os alunos em duas escolas em que os professores aceitaram atuar como supervisores e que estavam ministrando aulas e encontros síncronos via Google Meet, para que eles pudessem vivenciar essa realidade das aulas remotas.

Um dos grupos, de oito alunos, realizou esse estágio em uma escola estadual de Ensino Médio em Tempo Integral (EMTI), sob a supervisão de um professor de Geografia que também atuava como Coordenador das áreas de Ciências Humanas e Sociais Aplicadas. Além de acompanhar as aulas síncronas, esses estagiários tiveram momentos de elaboração de atividades, como vídeos para serem enviados aos alunos, elaboração de aplicação de regência, participação na orientação de um sábado letivo e participação como observadores de outros sábados letivos, participação das reuniões de módulo, com todos os professores e gestores da escola, e participação de reunião de grupo da área de Ciências Humanas e Sociais Aplicadas.

Nessas atividades, os estagiários tiveram contato com a nova dinâmica do ensino médio, com as disciplinas Projeto de Vida e Pós-Médio, também presenciaram a atuação do Instituto de Corresponsabilidade pela Educação 
FARIA, G. S; SILVA, A. P; AZEVEDO, S. C. Políticas neoliberais e ensino remoto emergencial...

(ICE) na educação de Minas Gerais e puderam sentir a pressão exercida sobre os professores para que esses conseguissem a participação dos alunos nas entregas das atividades do Regime Especial de Atividades Não Presenciais (REANP), por meio de atividades como busca ativa e apadrinhamento.

Como acompanharam atividades que ultrapassaram as atividades relacionadas às salas de aulas virtuais, foi possível presenciar outros campos do trabalho docente.

Os problemas relativos ao estágio supervisionado não se limitam à compreensão dos motivos do seu sucesso ou do insucesso enquanto uma atividade com um fim em si mesma dentro de uma disciplina do curso de formação de professores. Mas sim estabelece relações e tensões que envolvem o contexto no qual os sujeitos que o realizam estão inseridos, tendo em vista que é no espaço real onde ocorre a negociação dos saberes em disputa e que mobilizam as escolhas, a forma de pensar e atuar. (FRANÇA,2012, p. 28)

Para compreender melhor a observação realizada, buscou-se mostrar as contradições das políticas educacionais e como elas estão a serviço do sistema capitalista, utilizando para isso o materialismo histórico dialético.

Outra questão digna de nota refere-se ao fato de que para o materialismo histórico-dialético, conforme anteriormente indicado, o mundo empírico representa apenas a manifestação fenomênica da realidade em suas definibilidades exteriores. Nessa direção, Kosik (1976) afirma que a essência do fenômeno não está posta explicitamente em sua pseudoconcreticidade, não se revelando em sua forma imediata, mas, sim, pelo desvelamento de seu conteúdo. A construção do conhecimento científico representa, pois, um percurso de descortinar o pseudoconcreto em direção ao concreto, o que significa dizer, um processo de superação do pseudoconhecimento em direção ao conhecimento fidedigno acerca do real, apreendido em seu movimento e desvelado em suas contradições. (MARTINS; LAVOURA, 2018, p.229/230) 
FARIA, G. S; SILVA, A. P; AZEVEDO, S. C. Políticas neoliberais e ensino remoto emergencial...

Sobre as políticas educacionais e o materialismo, Deitos e Sobzinski (2015, p. 112) defendem que:

(...) considera-se importante na pesquisa sobre políticas educacionais a contribuição do materialismo histórico e dialético com o intuito de desvelar a política educacional em sua essência, considerar o embate de forças pelo qual é definida e implementada uma política educacional.

\section{REFLEXÕES SOBRE O ESTÁGIO NA FORMAÇÃO DE PROFESSORES.}

O estágio é um campo de conhecimento, e é através desse campo que a teoria, na formação do docente, encontra-se com a prática, ou seja, é através do estágio que o futuro professor possui o seu primeiro contato com a práxis. Na perspectiva do ensino tradicional, Pimenta e Lima (2005) colocam que o estágio sempre foi tido como a parte prática da formação profissional, entretanto muitos estagiários relatam que esta atividade é muito entediante por muitas vezes se limitar à observação das aulas, e sendo raros os momentos de realização de atividades docentes. Analisando essa perspectiva, existe uma fragilidade nessa concepção de estágio e a formação inicial continua demasiadamente ausente de práxis. Pimenta e Lima (2005) ainda acrescentam que, no caso da formação dos professores, muitos cursos não alicerçam a atuação do profissional, nem colocam a prática como caminho da teoria.

Com objetivo de superar essa visão e buscando levar os estagiários a vivenciar a práxis na docência, a disciplina Orientação de Estágio Supervisionado e Práticas Pedagógicas I organizou, em parceria com o professor supervisor, um estágio com atividades que envolvessem os estagiários com sua realidade profissional, de maneira mais próxima possível, possibilitando a eles perceberem os impactos das políticas educacionais nas condições de trabalho e na atuação do professor da educação básica. Kochhann (2015) reforça a necessidade de uma 
FARIA, G. S; SILVA, A. P; AZEVEDO, S. C. Políticas neoliberais e ensino remoto emergencial...

formação docente pautada na Tendência Histórico-Crítica, e afirma que essa deve ser pensada em pelo menos três aspectos: formação inicial, políticas educacionais e condições materiais de trabalho. Ainda sobre essa questão, Kochhann afirma que:

A Tendência Histórico-Crítica enquanto uma tendência contrahegemônica que apresenta uma organicidade de trabalho concreto considerando a prática social como fundante, aliada a práxis crítico-emancipadora pode vir a superar o pragmatismo ou praticismo do trabalho concreto e possibilitar uma visão mais crítica e emancipadora àqueles que estão em processo de formação. (KOCHHANN, 2015, p. 2).

A Tendência Histórico-Crítica apresentada por Saviani (2011) possui uma pedagogia contra hegemônica, que tem a práxis como caminho e sob o olhar dialético. Essa pedagogia Histórico-Crítica coloca uma concepção de que se deve conhecer tanto a prática educativa quanto a prática social.

Para tanto, é importante a formação inicial enquanto campo social das práticas educativas. O processo da formação docente constitui, consequentemente, a identidade docente de seu trabalho concreto. Segundo Kochhann (2015), isso significa que o trabalho, dos professores universitários, influencia na formação de futuros professores, e se esses professores universitários não compreendem o campo social do estágio, o procedimento teórico-prático, que configura a práxis, não se faz presente.

É preciso que o estágio ganhe caráter crítico, emancipador. É preciso avaliar que o docente vai se formando enquanto professor através de sua formação inicial e do seu trabalho no chão da sala de aula. Pimenta e Gonçalves (1990) relatam que o objetivo do estágio é possibilitar ao estagiário perspectivas de acordo com a realidade que ele se insere. No entanto, Pimenta e Lima ressaltam que: 
Como reflexão sobre as práticas pedagógicas das instituições escolares, o estágio não se faz por si. Envolve todas as disciplinas do curso de formação, constituindo um verdadeiro e articulado projeto político pedagógico de formação de professores cuja marca é a de alavancar o estágio como pesquisa. Poderá ocorrer, portanto, desde o início do curso, possibilitando que a relação entre os saberes teóricos e os saberes das práticas ocorra durante todo o percurso da formação, garantindo, inclusive, que os alunos aprimorem sua escolha de serem professores a partir do contato com as realidades de sua profissão. (PIMENTA E LIMA, 2006, p. 21)

Assim a busca por uma escola e a formação do docente, menos tradicional e mais emancipadora, faz com que todos saiam ganhando, o aluno, o professor em formação, o professor supervisor e o professor universitário.

\section{ENSINO REMOTO: DESAFIOS E OBSTÁCULO}

Diante do contexto pandêmico, desde março de 2020 o sistema de ensino tem recebido normativas, portarias e leis que visam diminuir os impactos no que se refere às questões educacionais. Segundo a Organização das Nações Unidas para a Educação, a Ciência e a Cultura (UNESCO), vários estudantes desde a Educação Básica até o Ensino Superior ficaram sem aulas em mais de 150 países devido à pandemia do coronavírus (UNESCO, 2021). A partir desse pressuposto, os professores (assim como os futuros professores) foram obrigados a utilizar a tecnologia como recurso.

Através desse contexto, o ensino remoto emergencial foi a alternativa proposta nacionalmente, e as plataformas digitais ganharam destaque nesse novo tipo de ensino. Mesmo com ferramentas tecnológicas atuantes no cotidiano escolar nacional, não são todas as escolas e alunos que possuem estrutura para lidar com um ensino que possui equipamentos tecnológicos como estrutura, pois até então eles eram pouco adotados no ensino regular, o que gerou grande desafio acerca de qual a melhor metodologia a ser utilizada através da ferramenta tecnológica. 
FARIA, G. S; SILVA, A. P; AZEVEDO, S. C. Políticas neoliberais e ensino remoto emergencial...

Sobre os desafios de utilizar tecnologias, Gonçalves e Avelino apontam que:

Com a imersão das Tecnologias Digitais da Informação e Comunicação (TDICs) em um curto período, percebe-se que a formação docente inicial e continuada, tem apresentado lacunas que carecem serem sanadas, em pleno isolamento social. Cabe ressaltar que educadores que antes não agregavam em seus planejamentos essas ferramentas tecnológicas foram obrigados a inseri-las em seus planos de ensino e de aulas. (GONÇALVES E AVELINO, 2020, p. 4).

Com relação à tecnologia de Informação e Comunicação (TIC), de acordo com o Instituto Brasileiro de Geografia e Estatística, foi feita a Pesquisa TIC Domicílios de 2018 e divulgou-se que 1 em cada 4 pessoas em território brasileiro não possui acesso à internet, ou seja, cerca de 46 milhões de brasileiros. Entretanto, o uso de telefone celular chega perto de 99,2 \% dos domicílios, sendo o principal meio de acesso à internet da população brasileira (IBGE, 2018).

Sendo assim, é possível identificar que a maioria da população tem acesso à internet, mesmo que seja via celular, mas não quer dizer que tenha acesso dentro de casa, acessando somente em locais públicos em que há a presença da internet gratuita ou dependendo de pacotes de dados das operadoras que são insuficientes para assistir aulas online além de serem extremamente caros. Tornase inviável, então, essa metodologia para todos os estudantes, sem a adoção de uma política pública de acesso à internet gratuita dentro de casa ou um subsídio financeiro.

Foi analisado que em vários momentos durante o estágio, dos poucos alunos que participavam das aulas síncronas, a entrada e saída das salas virtuais era constante, muito provavelmente em função da oscilação da internet da pessoa, assim como a dos próprios estagiários, que tiveram dificuldades de dar a regência devido à péssima internet ou dispositivo eletrônico que ou não funcionava a câmera ou o microfone. Assim, percebe-se o quão desafiador é o 
FARIA, G. S; SILVA, A. P; AZEVEDO, S. C. Políticas neoliberais e ensino remoto emergencial...

ensino remoto emergencial.

Compreendendo essa questão que é estrutural em nossa sociedade e em como daqui pra frente mais metodologias que utilizam recursos tecnológicos serão utilizadas, Gonçalves e Avelino colocam que:

(...) as instituições de ensino têm buscado ampliar a formação inicial e continuada, no uso das novas tecnologias e das metodologias ativas, com o intuito de quebrar paradigmas arraigados do ensino tradicional. Mas, tantos esforços pedagógicos e financeiros não se traduziram efetivamente no empenho de todos, pois as tecnologias sofrem mutações e os educadores não têm acompanhado, sempre, o avanço dessas TDICs. (GONÇALVES E AVELINO, 2020, p. 11)

Os professores, devido a diversos fatores como carga horária de trabalho elevada, baixa remuneração e inadequadas condições de trabalho, acabam não conseguindo manter uma formação continuada de forma que acompanhe a evolução da tecnologia e seu uso pedagógico, para isso é importante que os sistemas de ensino valorizem o professor e criem condições que os permita realizar uma formação continuada adequada.

É importante, ainda, compreender os desafios dos estudantes de comparecerem em sala de aula virtual com a existência de uma crise sanitária e econômica global. Tendo conhecimento da dificuldade de acesso à internet, devido à questão social, a Secretaria Estadual de Educação de Minas Gerais não tornou obrigatória a presença síncrona dos alunos em sala de aula. Para cumprir a presença, contabilizando a carga horária obrigatória, foi criado o Plano de Estudos Tutorado (PET) onde o aluno, para concluir o semestre, realiza as atividades presentes neste material. Os alunos que não possuíam acesso à internet podiam retirar o PET impresso na escola e, após realizar as atividades, enviava para o professor de forma virtual ou entregava o PET impresso para que a carga horária fosse contabilizada. 
FARIA, G. S; SILVA, A. P; AZEVEDO, S. C. Políticas neoliberais e ensino remoto emergencial...

Sobre a ausência de alunos em sala de aula, em várias reuniões que os estagiários participaram, os professores mencionavam que muitos dos alunos do ensino médio começaram a trabalhar durante a pandemia, devido à perda de empregos de alguns familiares e o aumento do custo de vida no contexto de crise sanitária e econômica. Ou seja, o aumento da desigualdade social no Brasil nesse momento afetou indiscutivelmente a educação básica. A ausência dos alunos é causada por fatores que ultrapassam o acesso à internet e faz parte de uma questão estrutural da sociedade.

\section{A VIVÊNCIA DO ESTÁGIO E A POLÍTICA NEOLIBERAL NA EDUCAÇÃO}

O estágio no ensino remoto permitiu algumas vivências onde foi possível identificar como as políticas neoliberais, que apresentam como características o combate ao Estado de Bem-Estar Social, suscitando o desaparelhamento do Estado, o que favorece as privatizações e a política de mercado que estão presentes na escola e limitam a autonomia do professor, incentivam a meritocracia, valorizando o quantitativo em prol do qualitativo, por meio de uma visão empresarial. Analisando o Banco Mundial e as Políticas Educacionais Brasileiras, Mota Júnior e Maués afirmam que:

As condicionalidades, portanto, estariam a serviço da estratégia do BM de promover o ajuste estrutural macroeconômico necessário à inserção do Brasil e demais países periféricos no processo de globalização neoliberal, o que significou, no caso do Brasil a partir do governo de Collor de Melo (1990-1992), a radicalização da liberalização da economia, com as privatizações dela decorrentes, e a destruição de um precário Estado Social por meio de uma contrarreforma do Estado, cujos efeitos mais visíveis sobre a educação básica e superior são o avanço do setor privado, a precarização do público e a penetração dos mecanismos e valores de mercado sobre a gestão, o financiamento, a avaliação e a produção de conhecimento. (MOTA JÚNIOR E MAUÉS, 2014, p. 1137)

Um exemplo claro disso é a presença do ICE na escola, a parceria que o 
FARIA, G. S; SILVA, A. P; AZEVEDO, S. C. Políticas neoliberais e ensino remoto emergencial...

governo do estado de Minas Gerais tem com esse instituto permite que ele determine como a escola deve proceder, como os professores devem planejar suas aulas, como devem ser organizadas as reuniões e o controle das atividades que os professores desenvolvem com os alunos, por meio de planilhas.

Dentre as ações do ICE destaca-se neste texto a definição do aluno protagonista. Em reunião acompanhada no estágio, os curadores e especialistas do ICE afirmaram que os alunos que são definidos como protagonistas possuem um papel importante de incentivar a turma a realizar as atividades do PET, esse formato passa responsabilidade do sistema aos jovens e também reforça a ideia da meritocracia e de um tratamento que pode gerar a desigualdade entre os alunos.

O que é ser protagonista? Como montar um clube na minha escola? Como deve ser organizada a semana de acolhimento? Essas são algumas questões que surgiram ao longo dos primeiros dias da "Formação em ações protagonistas", da qual participam cerca de 420 jovens de 71 escolas estaduais que oferecem a educação integral no ensino médio. O encontro teve início na terça-feira (5/11) e será realizado até esta quinta (7/11).

Os estudantes que participam da formação foram selecionados por serem protagonistas, se envolverem ativamente nas atividades desenvolvidas nas instituições de ensino onde estudam e por terem perfil multiplicador. Ao retornarem para suas escolas, eles serão os responsáveis por repassar todo o conteúdo da formação para os colegas e organizar, para o próximo ano, a semana de acolhimento para novos alunos. (AGÊNCIA MINAS, 2019)

Esse formato de aluno protagonista impacta diretamente na organização coletiva dos alunos, como ocorria em grêmio estudantil ou de forma mais organizada nas ocupações das escolas que ocorreram em vários estados do país, ações que possibilitam uma formação política aos alunos onde os mesmos se colocavam contra algumas políticas públicas e faziam suas reivindicações. Nesse formato de protagonista, o aluno é escolhido pela escola e recebe uma formação 
FARIA, G. S; SILVA, A. P; AZEVEDO, S. C. Políticas neoliberais e ensino remoto emergencial...

para agir, conforme o sistema orienta, sem questionar o sistema imposto.

Outro elemento importante de se destacar e que pode estimular o individualismo na juventude do ensino médio é a disciplina Projeto de Vida. Segundo a Secretaria Estadual de Educação de Minas Gerais:

Estimular o estudante a se autoconhecer e focar em aonde deseja chegar. É assim que os professores de Projeto de Vida irão atuar nas escolas estaduais que ofertam a educação integral de nível médio. Ao longo desta semana, os educadores participaram de uma formação que teve por objetivo dar suporte e orientações para o desenvolvimento do conteúdo nas salas de aula. (MINAS GERAIS, 2019).

Identificamos na disciplina Projeto de Vida uma perspectiva neoliberal pautada na meritocracia, onde os materiais propostos para os alunos trazem questões ditas de autoconhecimento, habilidades socioemocionais ou de preparação para o mercado de trabalho (Figura 1).

Figura 1: Sumário do PET de Projeto de Vida.

\section{SUMÁRIO}

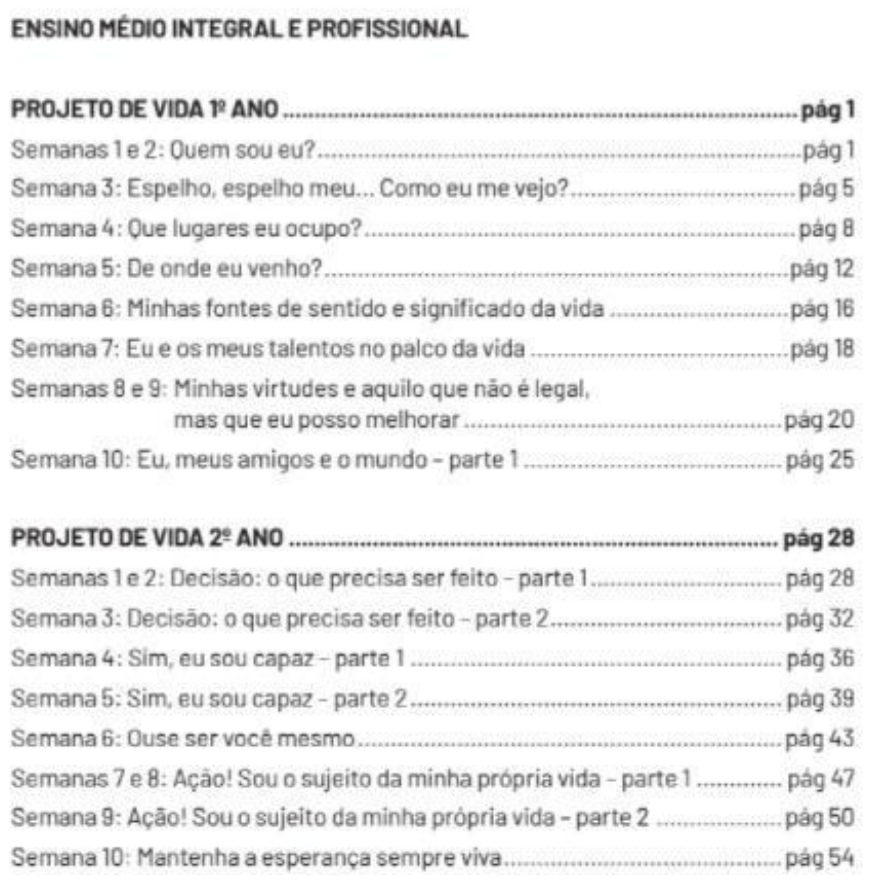


FARIA, G. S; SILVA, A. P; AZEVEDO, S. C. Políticas neoliberais e ensino remoto emergencial...

Fonte: MINAS GERAIS, 2021.

Os alunos criam um projeto para a sua vida, como se não houvesse obstáculos, onde basta ter um objetivo e foco desse ensino que será possível de ser alcançado. Existe a criação do sonho do aluno para aquele objetivo, uma esperança daquela realidade, mas sem haver uma política pública capaz de colocar em prática, tirando todo seu senso crítico e de coletividade, o qual é de suma importância no contexto atual, privilegiando as individualidades.

Essa situação reforça a hipótese de que o ideal do ensino médio integral para todos os jovens tem como objetivo o controle da juventude, que historicamente é questionadora e busca alternativas que muitas vezes não são colocadas pelo sistema vigente.

Outra temática importante de se destacar é o Conselho de Classe. Por meio do acompanhamento de reuniões de conselho de classe no estágio foi possível perceber que o conselho de classe numa escola pública é fundamental para a permanência do estudante na escola, pois é através dele que a escola pode tomar medidas de como atuar com esse aluno no próximo semestre ou ano letivo.

Ângela Dalben (2004) coloca que o Conselho de Classe é um órgão colegiado, que faz com que os professores de diversas disciplinas atuem juntamente com a equipe pedagógica da escola. Através desse colegiado, todos os participantes refletem sobre o desempenho de cada aluno das turmas em que atuam, e também avaliam as ações individuais e coletivas.

Entendo que a cidadania se constrói também dentro da escola e no trabalho conjunto dos professores e alunos por meio do processo ensinoaprendizagem. O conselho de classe é um importante espaço para praticar uma cidadania reflexiva de como podemos avaliar o aluno de acordo com sua realidade, para então ser avaliado de forma justa e cidadã. Na escola campo de estágio existia a presença dos alunos líderes de sala no conselho de classe, 
FARIA, G. S; SILVA, A. P; AZEVEDO, S. C. Políticas neoliberais e ensino remoto emergencial...

entretanto a abordagem é tão hierárquica, que é complicado estabelecer um certo diálogo entre aluno e professor nesse espaço. Vitor Henrique Paro coloca um paradoxo para o ensino fundamental, mas que também recai para o ensino médio:

Não deixa de ser paradoxal que a escola pública, lugar supostamente privilegiado do diálogo e do desenvolvimento crítico das consciências, ainda resista tão fortemente a propiciar, no ensino fundamental, uma formação democrática que, ao proporcionar valores e conhecimentos, capacite e encoraje seus alunos a exercerem ativamente sua cidadania na construção de uma sociedade melhor (PARO, 2000, p. 25).

Como foi definido pela escola campo de estágio, devido à situação pandêmica e o ensino remoto emergencial, todos os alunos possuem um professor tutor, que o acompanha, que possui o contato de celular do mesmo e da família, para que caso tenha alguma situação de defasagem pelos métodos escolhidos no atual contexto, ele entre em contato com o aluno ou familiar, para saber das atividades, ou que mande as atividades dentro do prazo estabelecido. Acredito que seja de grande importância a presença do professor tutor nesse contexto, devido a todos os desafios apresentados anteriormente neste texto. No entanto, essa estratégia aumenta a carga de trabalho do professor, e mesmo tendo consciência desse processo, os professores assumiram essa estratégia de tutor, mostrando como a escola e os professores estão preocupados com os seus alunos, mesmo diante de tanta pressão que sofrem.

Ao acompanhar as diversas atividades escolares foi possível perceber que há uma busca da escola por compreender a real situação do aluno no ensino remoto emergencial, mas quando esse fato se recai para o conselho de classe, aparecem os limites dessa prática. É nesse momento que os professores relatam a situação dos alunos que não entregam as atividades propostas pelo PET, criam estratégias para que esses alunos consigam entregar essas atividades, como 
FARIA, G. S; SILVA, A. P; AZEVEDO, S. C. Políticas neoliberais e ensino remoto emergencial...

ampliar o prazo de entrega por exemplo, mas quando não conseguem sucesso nessas ações acabam entregando o nome do aluno para ser levado para o Conselho Tutelar, órgão encarregado por zelar pelos direitos da criança e do adolescente.

Assim, todo o entendimento do processo do professor tutor é só de cobrança das atividades, que contam como presença, mas a situação do aluno, mesmo que dificultosa, de permanecer em sala de aula virtual ou de entregar o PET não é levada em conta, tendo em vista a sua realidade e a desigualdade social, ou seja, as ações dos professores e dos gestores possuem limitações que esbarram na desigualdade social.

Assim, é possível afirmar que o Conselho de Classe é um dos momentos estruturantes da permanência do aluno na escola. É através dele que é possível analisar diferentes pontos de vista, tanto de vários professores de cada disciplina, quanto do tutor e até mesmo do líder de sala, bem como os desafios que configuram a presença do aluno na escola. Se existisse um conselho de classe cidadão, ele em primeiro momento teria como objetivo analisar e avaliar a realidade do aluno dentro e fora da sala de aula, e a partir dessa análise saber qual medida tomar para que o mesmo continue em sala de aula ou na escola adquirindo o saber, ao invés de ser levado ao Conselho Tutelar, que pode gerar inúmeras consequências à família e ao aluno, sabendo dos desafios que o mesmo sofre devido à desigualdade.

Com relação às reuniões gerais acompanhadas, foi possível identificar a cobrança sobre os professores para que os alunos realizem as tarefas. Era perceptível a preocupação da gestão e dos professores com a falta de participação dos alunos nas aulas online e na entrega das atividades do PET. Apesar do esforço da escola para tentar chegar ao máximo de alunos, muitas vezes ela não conseguia. Em nossa análise, podemos inferir que a forma que o REANP foi organizado pela SEE desmotiva o aluno a participar das atividades, o que dificulta 
FARIA, G. S; SILVA, A. P; AZEVEDO, S. C. Políticas neoliberais e ensino remoto emergencial...

o trabalho da escola.

Existe uma grande contradição nesse processo, pois o mesmo sistema que padroniza e estimula um ensino tradicional, impõe sábados letivos para que sejam realizados trabalhos diferenciados.

De acordo com a Resolução SEE n4.494, de 05 de fevereiro de 2021, em seu artigo 7,

Parágrafo único: A escola deverá utilizar-se do número de sábados letivos necessários para composição de seu calendário, observada a garantia de 100 dias letivos para a organização semestral e 200 para a organização anual, a saber:

I- 08 sábados letivos no primeiro semestre para compor o calendário previsto no Anexo I desta Resolução, mais;

II- 11 sábados letivos no segundo semestre para compor o calendário previsto no Anexo I desta Resolução, mais;

III- o quantitativo de sábados letivos necessários para compor o calendário de cada escola em virtude dos feriados municipais e outros motivos justificáveis. (MINAS GERAIS, 2021)

E as escolas não tiveram autonomia para definir os temas dos sábados letivos, pois foi elaborado um documento para orientar a organização desses sábados. O documento "Os melhores sábados de sua vida":

As aulas ofertadas nos sábados letivos devem abarcar atividades diferenciadas da rotina escolar, com intuito de complementar a formação dos estudantes e ampliar as possibilidades de aprendizagem. Os sábados letivos deverão ser organizados contemplando dois focos, o primeiro composto por temáticas interdisciplinares e multiculturais e o segundo pela culminância das intervenções pedagógicas. É importante ressaltar que as atividades referentes a este último foco, culminância das intervenções pedagógicas, devem ser elaboradas em diálogo com as orientações e diretrizes pedagógicas presentes neste documento. (MINAS GERAIS, 2021A)

Os sábados letivos já possuíam os temas propostos anteriormente pelo 
FARIA, G. S; SILVA, A. P; AZEVEDO, S. C. Políticas neoliberais e ensino remoto emergencial...

cronograma do Novo Ensino Médio, assim cada área do conhecimento ficava por conta de organizar junto com os alunos o roteiro desses sábados. O sábado onde os estagiários participaram com os alunos foi o da Ciências Humanas e Sociais, onde foi possível ver uma construção mais horizontal, definindo junto com os alunos os assuntos que eles gostariam de apresentar dentro da temática imposta pela SEE, e os alunos também foram protagonistas nas apresentações. Mas isso não aconteceu em todos os sábados letivos, pois em muitos os alunos não tinham autonomia para criticar os temas e não trouxeram conceitos que questionem a estrutura do sistema vigente. Fizeram correlações das propostas dos projetos de vida com o sábado letivo, onde os alunos apresentavam seus projetos criados na disciplina, assim reafirmando cada vez mais essa política meritocrática para toda a escola.

\section{CONSIDERAÇÕES FINAIS}

Tendo em vista a situação tanto da formação docente quanto do ensino básico de estarem em ensino remoto emergencial, é delicado analisarmos o processo do estágio nessa situação. É algo novo para ambas instâncias, o que nos leva a uma análise quase que inconsistente, pois pode mudar em pouco tempo ou continuar da mesma maneira, diante do cenário ainda instável. Contudo, após mais de um ano nessas circunstâncias, é essencial que seja analisada essa situação, pois estamos falando da formação básica da população brasileira e como isso pode causar inúmeras consequências em sua formação futura.

Sendo assim, o estágio foi de grande aprendizado, mesmo que nessa situação, pois foi possível compreender a importância da formação docente e como o estágio se c oloca na interação da teoria com a prática, e poder mesmo que pouco atuar na práxis foi de grande relevância no processo de tornar-se professor.

Já no que diz respeito aos desafios do ensino remoto emergencial e a 
FARIA, G. S; SILVA, A. P; AZEVEDO, S. C. Políticas neoliberais e ensino remoto emergencial...

utilização de tecnologias como metodologia, os professores necessitam urgentemente de uma formação continuada ou de possuir essa própria formação na iniciação à docência. Entretanto, de nada adianta essa formação se não há recurso público ou diminuição da desigualdade social para que os alunos também possuam acesso a essa metodologia.

Por último, o avanço da política neoliberal no ensino básico coloca inúmeras consequências para a formação do aluno. Essa prática empresarial pautada no ensino retira todo o processo de ensino-aprendizagem como foco, e traz para a escola uma função de formação de mão de obra. Não colocam o aluno como questionador de sua realidade e do ensino que está tendo, mas sim como reprodutor de uma lógica de mercado, onde o mesmo é colocado como único formador da sua vida, e que todos os obstáculos que ele encontra são criados por ele mesmo e não pelo sistema vigente.

\section{REFERÊNCIAS BIBLIOGRÁFICAS}

DALBEN, Ângela Imaculada Loureiro de Freitas. Conselho de Classe e Avaliação. Campinas, São Paulo: Papirus, $2004 . \quad$ Disponivel em: http://www.educacaotiete.sp.gov.br/wp-content/uploads/2014/11/O-papel-doConselho-de-Classe-no-processo-avaliativo.pdf. Acesso em: 15 de out, 2021.

DEITOS, Juliano Marcelino; SOBZINSKI, Janaina Silvana. O materialismo histórico e dialético: contribuições para a análise de políticas educacionais. Impulso, Piracicaba, 25(63), 101-118, 2015 .FNDE. Informe 09/2021 - COARE/FNDE Escolha PNLD 2021 - Projetos Integradores e Projeto de Vida, Brasília, fevereiro de 2021. Disponível em: https://www.fnde.gov.br/index.php/centrais-deconteudos/publicacoes/category/228-informes?download=14545:informen\%C2\%BA-09-2021-guia-pnld-2021. Acesso em: 18 de out, 2021.

FRANÇA, Sandra Stefani Amaral. Políticas para formação de professores : reflexões sobre o estágio supervisionado - do legal ao real. Dissertação de Mestrado. Programa de Pós-Graduação em Educação da Faculdade de Ciências e Tecnologia - Universidade Estadual Paulista - Campus de Presidente Prudente SP - Presidente Prudente, 2012135 f. Disponivel em: 
https://repositorio.unesp.br/handle/11449/92312. Acesso em: 15 de out, 2021. GONÇALVES, Carlos Luiz e PIMENTA, Selma Gariido. Revendo o ensino de $2^{\circ} \mathrm{Grau}$, propondo a formação do professor. São Paulo: Cortez, 1990. Disponibel em: https://www.passeidireto.com/arquivo/93131122/10542-texto-do-artigo-407901-10-20100722/7. Acesso em: 10 de ago, 2021.

GONÇALVES, Natalia Kneipp Ribeiro e AVELINO, Wagner Feitosa. Estágio Supervisionado em Educação no Contexto da Pandemia da Covid-19. BOCA, Ano II, vol. 4, $\mathrm{n}^{\circ}$ 10, Boa Vista, 2020. Disponível em: https://revista.ufrr.br/boca/article/view/AvelinoGoncalves. Acesso em: 8 de ago, 2021

IBGE - Instituto Brasileiro de Geografia e Estatística. O uso de internet, televisão e celular no Brasil. Rio de Janeiro: IBGE, 2018. Disponível em: <https://educa.ibge.gov.br>. Acesso em: 10 de ago, de 2021.

KOCHHANN, Andréa. FORMAÇÃO DOCENTEE TRABALHO CONCRETO: apontamentos pela Tendência Histórico-Crítica e Práxis Crítico-Emancipadora. EDUCERE, XII Congresso Nacional de Educação, 2015. Disponível em: https://educere.bruc.com.br/arquivo/pdf2017/24577_12699.pdf. Acesso em: 5 de ago, 2021.

MARTINS, Lígia Márcia.; LAVOURA, Tiago Nicola. Materialismo histórico-dialético: contributos para a investigação em educação. Educar em Revista, Curitiba, v. 34, n. $71, \quad$ p. 223-239, 2018. Disponivel em: https://www.scielo.br/j/er/a/75VNGFj5PH5gy3VsPNp3L6t/?format=pdf\&lang=pt. Acesso em: 14 de out, 2021.

MINAS. SECGERAL - Secretaria-Geral. Encontro reúne jovens das escolas estaduais que oferecem educação integral no ensino. Minas Gerais. 2019. Disponivel em: http://www.agenciaminas.mg.gov.br/noticia/encontro-reune-jovens-das-escolasestaduais-que-oferecem-educacao-integral-no-ensino. Acessado em: 20 de out, 2021.

MINAS. SEE/MG - Secretaria de Estado de Educação de Minas Gerais. Professores de Projeto de Vida participam de formação. Minas Gerais, 2019. Disponivel em: https://www2.educacao.mg.gov.br/component/gmg/story/10511-professores-deprojeto-de-vida-participam-de-formacao. Acessado em: 20 de out, 2021.

MINAS. SEE/MG - Secretaria do Estado de Educação. RESOLUÇÃO SEE N4.494 DE 05 DE FEVEREIRO DE 2021. Minas Gerais, 2021. Disponivel em: 
FARIA, G. S; SILVA, A. P; AZEVEDO, S. C. Políticas neoliberais e ensino remoto emergencial...

https://www2.educacao.mg.gov.br/images/documentos/RESOLU\%C3\%87\%C3\%8 3O\%20SEE\%20N\%C2\%BA\%204.494\%20DE\%2005\%20DE\%20FEVEREIRO\%20DE\%2 02021.pdf. Acessado em 20 de out, 2021

MINAS. SEE/MG - Secretaria de Estado da Educação, SDEB/MG - Subsecretaria de Desenvolvimento da Educação Básica, SPP/MG - Superintendência de Políticas Pedagógicas. Fortalecimento das Aprendizagens 2021 - Os Melhores Sábados Letivos da Sua Vida. Minas Gerais, 2021. Disponivel em: https://www.diaadianaescola.com.br/wp-content/uploads/2021/04/Os-melhoresSabados-Letivos-da-sua-Vida.pdf. Acessado em: 20 de out, 2021.

MINAS. SEE/MG - Secretaria do Estado de Minas Gerais. Plano de Estudos Tutorados - Volume 1. Minas Gerais, 2021. Disponivel em: https://drive.google.com/file/d/1iFJBR-zV50A1HpH4mS3lb0Eyzyl0xdjo/view, Acessado em: 30 de set, 2021.

MOTA JUNIOR, William Pessoa e MAUÉS, Olgaíses Cabral. O Banco Mundial e as Políticas Educacionais Brasileiras. Educação \& Realidade, vol. 39, núm. 4, outubro/dezembro, $2014 . \quad$ Disponível:

http://www.scielo.br/pdf/edreal/v39n4/10.pdf>. Acesso: em 21 nov. 2021.

PARO, Vitor Henrique. Educação Para a Democracia: o elemento que falta na discussão da qualidade do ensino. Revista Portuguesa de Educação, v. 13, n 01, p. 23-38, 2000. Disponivel em: https://www.anped.org.br/sites/default/files/gt_05_18.pdf. Acesso em: 5 de ago, 2021.

PIMENTA, Selma Garrido e LIMA, Maria Socorro Lucena. Estágio e Docência: diferentes concepções. Revista Poíesis -Volume 3, Números 3 e 4, pp.5-24, 2005/2006. Disponivel em: https://www.revistas.ufg.br/poiesis/article/viewFile/10542/7012. Acesso em: 5 de ago, 2021.

SAVIANI, Dermeval. Pedagogia Histórico-Crítica: primeiras aproximações. 9. ed. Campinas: Autores Associados, 2011. Disponivel em: file://C:/Users/Gabriel/AppData/Local/Temp/DermevalSaviani-Pedagogiahistricocriticaprimeirasaproximaes11edrevisada1.pdf. Acesso em: 5 de out, 2020

UNESCO-Organização das Nações Unidas para a Educação, a Ciência e a Cultura. Educação: da interrupção à recuperação. UNESCO [2020]. Disponível em: <https://pt.unesco.org/covid19/educationresponse>. Acesso em: 10/08/2021. 